\title{
Los procedimientos de elección de los gobernadorcillos de "igorrotes" en Filipinas a finales del siglo XIX ${ }^{1}$
}

\author{
Juan Antonio INAREJos MuÑoz \\ Consejo Superior de Investigaciones Científicas (España) \\ juan.inarejos@cchs.csic.es
}

Recepción: 4 de abril de 2013 / Revisión: 22 de junio de 2013

Aceptación: 11 de noviembre de 2013 / Publicación: diciembre de 2014

\section{RESUMEN}

En el artículo se analizan los procesos de selección de los gobernadorcillos de "igorrotes" a finales del siglo XIX en Filipinas y sus particularidades respecto al sistema empleado por la administración colonial en los pueblos de indios. Se desglosan los objetivos y las diferentes estrategias desplegadas para someter a estos territorios y poblaciones bajo la grandilocuente aspiración del progreso y la evangelización, maniobras que estuvieron jalonadas por prácticas corruptas en la cooptación de las élites nativas. A través de un enfoque comparativo se estudian los perfiles comunes y distintivos que entrañaron las elecciones en las poblaciones reducidas respecto a las votaciones celebradas entre las principalías de zonas ya incorporadas al redil colonial. En último lugar se desvelan los factores que determinaron la selección de los principales "igorrotes" en función de criterios socioeconómicos, militares y religiosos, a partir de un variado número de casos de estudio.

Palabras clave: Colonialismo, elecciones, poder local, élites indígenas, igorrotes, Filipinas, siglo XIX.

The elections of igorot gobernadorcillos in the Philippines at late $19^{\text {th }}$ century

\begin{abstract}
This article analyzes the procedures used at the end of the $19^{\text {th }}$ century for the selection of the "Gobernadorcillos" of the "Igorrotes" of the Philippines, and its peculiarities, in comparison to the system implemented by the colonial administration for the Indian villages. The article outlines the objectives and strategies employed to subjugate the peoples of these territories under the grandiloquent aspiration of progress and evangelization; strategies that were marked by corrupt practices used in the co-optation of the native elites. The common and distinctive profiles that characterized elections in smaller villages, are comparatively studied with respect to the elections held in the principal towns of regions already incorporated into the colonial sheepfold. Lastly, based on the analysis of a varied number of case-studies, the article uncovers the factors that determined the selection of the principal "igorrotes" with regard to socioeconomic, military and religious criteria.
\end{abstract}

Keywords: Colonialism, Elections, Local Power, Indigenous Elite, Igorots, Philippines, $19^{\text {th }}$ century.

1 Trabajo realizado en el marco del Proyecto Nacional de I+D+I titulado "Imperios, Naciones y Ciudadanos en Asia y el Pacífico (HAR-2009 14099-C02-02)”, dirigido por Ma Dolores Elizalde Pérez-Grueso. 
Sumario: 1. Introducción. Acerca de los procesos de selección de las élites dirigentes indígenas. 2. La institucionalización de las rancherías de "igorrotes": estrategias y dificultades. 3. Las elecciones de gobernadorcillos en las poblaciones "reducidas": el caso de Rosario (La Unión). 4. Las inquisiciones sobre gobernadorcillos "igorrotes": recaudadores, paramilitares e infieles a examen. 5. Conclusiones. 6. Referencias bibliográficas.

\section{INTRODUCCIÓN. ACERCA DE LOS PROCESOS DE SELECCIÓN DE LAS ÉLITES DIRIGENTES INDÍGENAS}

La conquista y colonización española de Filipinas no resultó un proceso acabado. A finales del siglo XIX el norte del archipiélago contó con amplias zonas, habitadas por comunidades catalogadas peyorativamente por los colonizadores como "salvajes" o "infieles", que permanecieron en menor contacto o al margen de la influencia hispánica y determinaron la configuración de fronteras interiores ${ }^{3}$. Junto a los "moros" del sur musulmán, una parte importante de estas poblaciones situadas preferentemente al norte de la isla de Luzón no fueron evangelizadas -o parcialmente- y gozaron de modelos de organización social diferentes a los sancionados por los colonizadores peninsulares". También conocidos como "igorrotes", habitaron preferentemente las montañas norteñas de Luzón ${ }^{5}$.

A pesar de que también existieron comunidades de igorrotes reducidas y evangelizadas, los contactos entre estos grupos y los españoles fueron limitados y estuvieron marcados por continuos enfrentamientos militares, particularmente desde finales del siglo XVIII y durante la segunda mitad del XIX. A partir de esta última fecha la administración colonial experimentó un renovado interés por incorporar las comunidades bajo el yugo colonial por razones económicas, religiosas y militares ${ }^{6}$, marcadas por la "reducción" de poblaciones no sometidas, la destrucción de plantaciones ilegales de tabaco previas al desestanco, la apertura de nuevas vías de comunicación, la ejecución de operaciones bélicas o la seducción ejercida por el oro de Apayao ${ }^{7}$.

2 Huelga recordar que la utilización de esta serie de epítetos a lo largo del artículo responde a la necesidad de utilizar y desgranar los conceptos y significados que entrañaron en el contexto colonial, marcados por el racismo, el eurocentrismo y el empleo del lenguaje como un arma más de dominio colonial.

3 Las comunidades de "igorrotes", reducidas o sin reducir, se ubicaron preferentemente en las circunscripciones de Abra, Bontoc, Benguet, Cagayán, Ifugao, Ilocos Norte, Ilocos Sur, Isabela, La Unión, Lepanto y Nueva Vizcaya.

4 Los primeros contactos de los peninsulares con estos grupos étnicos, en ScotT, 1974.

5 Para profundizar en el origen del término y los diferentes grupos étnicos englobados en él, véase Scott, 1988, p. XIII; Zamora, 1992, pp. 15 y 27; y SÁnchez Gómez, 2003, pp. 19-21. Para la reformulación de la categoría de "infieles", elaborada por el colonialismo español, en la de "no cristianos" bajo dominio estadounidense, véase KRAMER, 2006, pp. 35-86; 2011, pp. 138; y CAMACHO, 2002, pp. 43-74.

6 Englobado dentro del más amplio interés que despertó Filipinas para la metrópoli durante esta misma etapa, subrayado por ElizALDE, 2002, pp. 123-142.

7 Motivaciones analizadas en SÁnchez Gómez, 2003, p. 20; Fradera, 2005, p. 479. 
Mapa 1

Mapa provincial de Filipinas a finales del siglo XIX

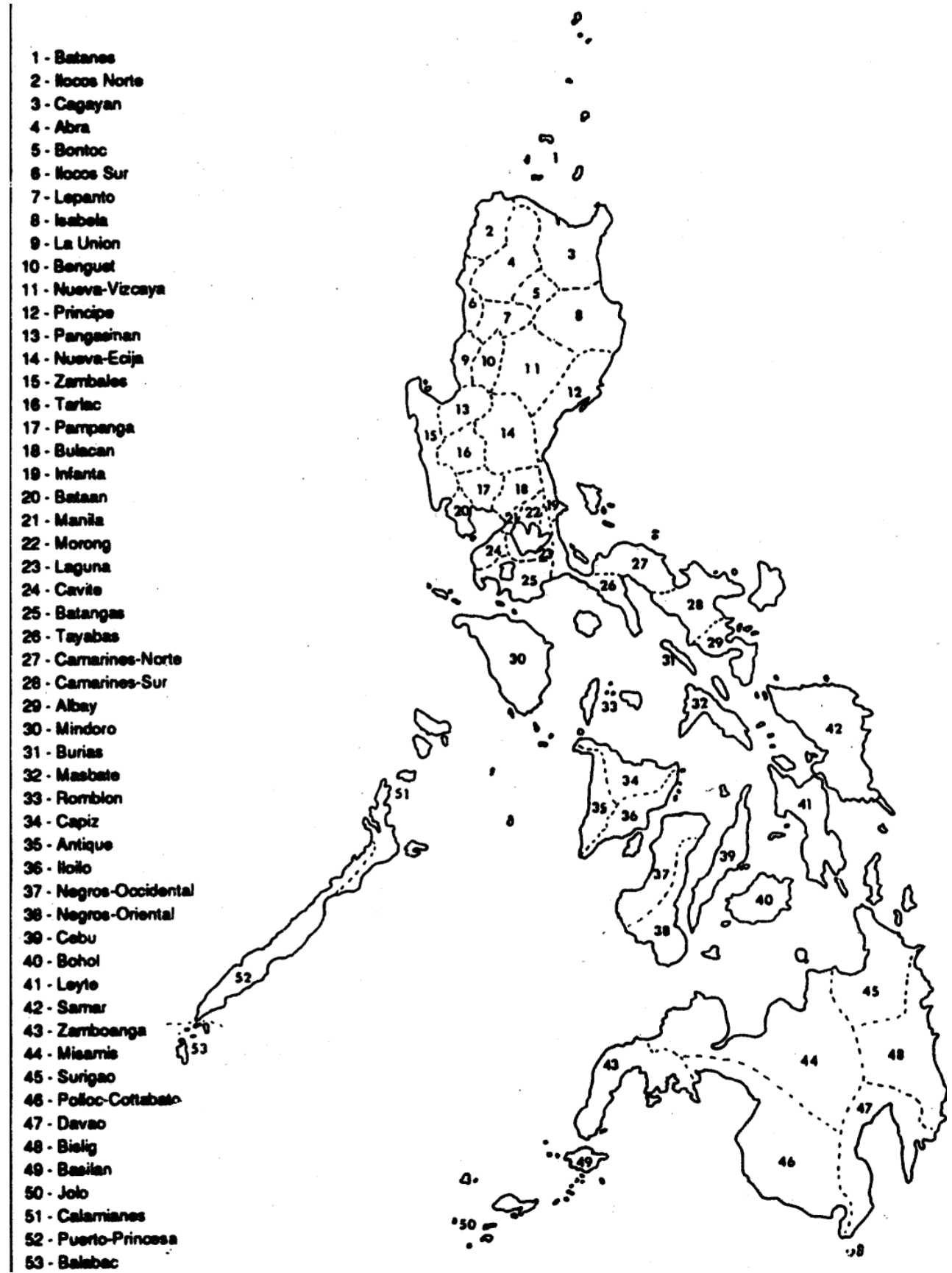

Fuente: Huetz de Lemps, 1990, p. 311. 
Según John Blanco, las rancherías de "igorrotes", una de las denominaciones de los barrios o visitas alejadas de las localidades matrices habitadas por población seminómada, fueron uno de los blancos predilectos de la política de reducciones orientada a incrementar la recaudación tributaria y la conversión al cristianismo ${ }^{8}$. Estos núcleos gozaron de una organización que entrañó una serie de diferencias respecto a la de los pueblos de indios, particularmente en relación al nombramiento de sus gobernadorcillos. A excepción de los escasos paréntesis en los que permaneció vigente la Constitución de Cádiz y el Estatuto Real, estas autoridades locales fueron los únicos espacios de poder tangibles para las elites filipinas?.

Los gobernadorcillos eran las autoridades encargadas de dirigir los pueblos de indios y los cabezas de barangays existentes en cada pueblo. Hasta la reforma de 1893 fueron designados con un término peyorativo que se generalizó a partir de 1696 . Las estructuras de organización socioeconómicas prehispánicas, los jerarquizados núcleos de población conocidos como barangays ${ }^{10}$, fueron integrados en las nuevas encomiendas creadas tras la conquista. Los orígenes del cabeza de barangay, de raíz nobiliaria, se remontan a los jefes de los diferentes grupos territoriales y familiares prehispánicos del mismo nombre ${ }^{11}$. El barangay era un grupo de tributantes que podían vivir en diferentes barrios de una localidad, al frente de los cuales se situó el cabeza de barangay. Esta autoridad gozó de carácter hereditario y vitalicio hasta 1789, aunque también se accedió a este cargo mediante un nombramiento de las autoridades españolas. A partir de esta fecha pasó a ser de carácter electivo y esta dualidad fue suprimida. Y, al igual que los gobernadorcillos, gozaron de amplias potestades tributarias, de orden público y de ciertas prerrogativas como la exención de las prestaciones personales, militares y contributivas. Es decir, el régimen gubernativo implantado estuvo regido por un sistema político-administrativo mixto que alternó mecanismos de dominación directa e indirecta. Las élites nativas prehispánicas, también conocidas como principalías, no fueron eliminadas y suplantadas por los peninsulares. Éstos les cedieron las riendas del poder local y delegaron en ellas nuevas funciones ${ }^{12}$.

En los pueblos de indios, la selección de los candidatos a gobernadorcillo no sufrió cambios sustanciales hasta la intervención estadounidense y únicamente la reforma finisecular propuesta por Maura introdujo las modificaciones más reseñables ${ }^{13}$. Entre los cabezas de barangay que formaban cada principalía se realizada un sorteo, con carácter bianual a partir de 1862, que designaba doce electores. Éstos y el gobernadorcillo saliente eran los trece encargados de elegir una terna formada por los tres individuos más votados ${ }^{14}$. El resultado era elevado al Gobernador Civil, quien proponía al Gobernador General de Filipinas al individuo de esta terna que consideraba más

8 BLANCO, 2009, p. 45.

9 Fradera, 2008, pp. 9-30.

10 Sсотт, 1997.

11 Sánchez Gómez, 1990, pp. 81-116; Huetz de Lemps, 1998, pp. $28-48$.

12 La implantación y organización de la administración colonial, en Phelan, 2011 [1959]; Hidalgo Nuchera, 1995; Alonso Álvarez, 2009, pp. 79-117.

13 El corpus legislativo, en SÁnchez Gómez, 1991, pp. 199-211 y 354-376; Azcárraga, 1871; Blumentritt, 1881.

14 Proceso electivo que despertó la atención de autores como Jesús, 1978, pp. 142-156; MAY, 1987, pp. 30-52; SÁnchez Gómez, 1989, pp. 53-61; BANKoff, 1992, pp. 679-700. 
apto, o bien decretaba, si procedía, la anulación de la votación. A la hora de discriminar, el Gobernador Civil contó con los minuciosos informes elaborados sobre cada uno de los miembros de la terna por parte de la Guardia Civil y el administrador de Hacienda, pesquisas que se unieron a las inquisiciones elaboradas por los párrocos.

\section{LA INSTITUCIONALIZACIÓN DE LAS RANCHERÍAS DE "IGORROTES": ESTRATEGIAS Y DIFICULTADES}

Este mecanismo electivo fue empleado por las autoridades coloniales para seleccionar a las élites indígenas de los pueblos de indios. No obstante, la elección de gobernadorcillos sufrió importantes variaciones en las zonas fronterizas habitadas por grupos étnicos seminómadas que escaparon al control directo de los peninsulares. El análisis de las actas de nombramientos de gobernadorcillos de estas demarcaciones permite desvelar las particularidades generadas por el nombramiento de estas autoridades para las rancherías de "igorrotes". Una amplia nómina de estos problemas fueron expuestos en una comunicación que el Gobernador Político-Militar de la provincia de Lepanto envió el 11 de mayo de 1888 a la sección de Gobierno en Manila ${ }^{15}$. En ella el Gobernador Político-Militar informó del nombramiento de un gobernadorcillo y tres justicias para cada una de las rancherías de Bacong y Banguinay (provincia de Lepanto) ${ }^{16}$. Estos nombramientos fueron solicitados por los principales de estos núcleos ante esta autoridad. Ambas rancherías se encontraban "alzadas", es decir, no sometidas formalmente a la jurisdicción colonial. Los nombramientos fueron aprobados por el Gobernador General de Filipinas. No obstante, era necesario que el Gobernador Político-Militar remitiese una relación nominal de los nuevos gobernadorcillos y munícipes de las citadas rancherías para que el Gobierno General pudiese expedir los correspondientes títulos. Este trámite fue aprovechado por la autoridad provincial para desglosar algunas de las particularidades del método electivo y funciones de los gobernadorcillos de rancherías:

como rancherías de "igorrotes", sus gobernadorcillos y justicias no tienen las responsabilidades que marcan los reglamentos para los de los pueblos cristianos, pues aquellos solo sirven para hacer cumplir algunas órdenes, y que por esta razón solo se les ha provisto hasta ahora de un nombramiento espedido [sic] por el jefe del distrito, el cual se les recoge cuando cometen alguna falta, nombrando otros en su lugar, acto que es considerado por ellos como un severo castigo ${ }^{17}$.

15 Expediente de nombramiento de gobernadorcillo de Bacong y Banguinay, 1888. Philippine National Archives, Manila (en adelante PNA), Serie Elecciones de Gobernadorcillos (en adelante SEG), provincia de Lepanto, legajo 116, rollo 6364 (se ha consultado la copia de esta documentación albergada en el Centro de Ciencias Humanas y Sociales del CSIC, Madrid). La organización de la administración colonial filipina en el siglo XIX, en Celdrán, 1994; HuetZ de Lemps, 2006; ElizAlde, 2009, pp. 45-78. En general, las demarcaciones y distritos habitados por "igorrotes" del norte de Luzón estuvieron administradas por gobernadores militares.

16 La provincia de Lepanto se desgajó en 1852 de la provincia de Abra. Bacong fue una de las rancherías que sufrieron expediciones de castigo dirigidas por Urbano y Montero en 1865; PérEz, 1902, pp. 54-55.

17 Expediente de nombramiento de gobernadorcillo de Bacong y Banguinay, 1888. PNA, SEG, provincia de Lepanto, legajo 116, rollo 6364. 
El tradicional método electivo era sustituido por una designación directa de la autoridad político-militar. Frente a las amplias funciones delegadas a los gobernadorcillos de los pueblos de indios ${ }^{18}$, los gobernadorcillos de rancherías ostentaron menos prerrogativas y su título, expedido por el jefe provincial, les era retirado como castigo cuando cometían alguna infracción. El carácter transitorio otorgado por la administración a estos cargos derivó de las particulares características de estos núcleos y grupos de población, según se encargó de precisar el Negociado del Gobierno General:

Como las rancherías de "igorrotes" sometidos no están constituidas civilmente, dada la facilidad con que se remontan, cuando sin las debidas conveniencias se trata de hacerles cambiar sus usos y costumbres, sus gobernadorcillos y ministros de justicia no tienen los derechos ni los deberes que las leyes determinan para los pueblos ya más civilizados, y de ahí el que los nombramientos hayan venido haciéndose hasta la fecha por los jefes de los distritos, como manifiesta el de Lepanto; pero en opinión del jefe de Negociado que tiene el honor de dirigirse a V. E. deben de hacerlo en títulos impresos y a nombre de V. E. a fin de darles mayor prestigio y solemnidad, con la circunstancia que deberá expresarse al pie de aquellos de ser gratis; pues es notorio y público que estos infieles rechazan la civilización y el cristianismo porque dicen que se les exigen mayores contribuciones y gastos ${ }^{19}$.

El sugerente testimonio aportado por el Negociado permite desentrañar las estrategias desplegadas por la administración para incorporar al redil colonial a esta población "sin civilizar". En primer lugar aconsejó maniobras conciliatorias que no supusiesen un cambio radical en su organización socio-económica ${ }^{20}$. En segunda instancia sugirió otorgar relevancia simbólica a los títulos concedidos, honores que inicialmente debían ser gratuitos para evitar un rechazo motivado por las exacciones anejas a la "civilización" y el "cristianismo" 21 . De forma velada, el Negociado reconoció el incremento de las exacciones económicas como uno de los motores que empujó a la metrópoli a intentar ampliar su dominio amparado en la grandilocuente aspiración del progreso y la evangelización ${ }^{22}$. No obstante, se propuso postergar esta aspiración a medio y largo plazo para evitar un choque "cultural" -y/o económico- a corto pla$\mathrm{zo}^{23}$. Se aconsejó hacerles entrar en el "mundo civilizado" de forma progresiva:

\footnotetext{
18 Véanse algunas de estas funciones en FeCED y Temprado, 1867.

19 Expediente de nombramiento de gobernadorcillo de Bacong y Banguinay, 1888. PNA, SEG, provincia de Lepanto, legajo 116, rollo 6364.

20 Estrategia definida como política de atracción por Ángel Pérez, misionero en estas demarcaciones a finales del siglo XIX y autor de una sugerente obra "etnográfica” sobre los “igorrotes"; PÉrEZ, 1902, p. 103.

21 Algunos gobernadores cobraron por los nombramientos de gobernadorcillo, justicias o cabezas de barangay, con la consiguiente obligación de renovar los títulos anualmente, práctica que favoreció la multiplicación de rancherías con el objetivo de incrementar la recaudación por títulos. No resulta casual el énfasis puesto por el Negociado en la gratuidad de los títulos.

22 Tras la quiebra del sistema articulado en torno al Galeón de Manila, la inestabilidad metropolitana y la necesidad de obtener fondos a través de monopolios fiscales y tributos personales durante el siglo XIX; FRADERA, 2005.

23 Para evitar este rechazo, el fraile agustino Ángel Pérez advirtió al Gobernador Emilio Terrero de la necesidad de aumentar los impuestos y trabajos obligatorios a los "igorrotes" que permaneciesen "infieles" para evitar que los "reducidos" y recién bautizados pagasen más impuestos que aquellos que no abrazaban el catolicismo: "El Gobierno, que jamás ha conocido sus propios intereses en el asunto, ha querido agravar la
} 
Ahora bien, Excmo. Señor, en la constitución de las rancherías sabe V. E. que hay mucho de vago e indeterminado, dadas las costumbres de los "igorrotes", que nunca se someten por completo a nuestra autoridad, que no se sujetan a vivir en pueblos y que no ocupan constantemente un sitio determinado; pues desconociendo las ventajas de la civilización, con suma facilidad, con razón o sin razón, con causa o sin ella, se alzan o remontan, yéndose a habitar los bosques en donde gozan de la omnímoda libertad del salvaje, sin reconocer otro freno que su capricho y absoluta voluntad. Estos hábitos no es fácil arrancar por medio de leyes, por disposiciones más o menos benignas y favorables. Para acostumbrarles a vivir en sociedad, para hacerles entrar en el concierto universal, preciso es irles atrayendo suave y paulatinamente, transigiendo en cuanto sea posible con sus costumbres y defectos; pues el quererlos sujetar de repente a una reglamentación determinada, sin contar en cada localidad con la fuerza coercitiva necesaria al efecto, podría ser peligroso y redundar en desprestigio nuestro ${ }^{24}$.

Esta magnánima estrategia en ocasiones fue sustituida o complementada con puntuales expediciones militares que intentaron someter estas comunidades, la fuerza coercitiva mencionada en el fragmento anterior, como las ejecutadas por Fernando Primo de Rivera en $1880^{25}$. La imposibilidad de contar con una presencia permanente de amplios efectivos coercitivos determinó la puesta en práctica de una estrategia conciliatoria que afectó al modo de nombrar los gobernadorcillos. Es decir, si la constitución de rancherías no seguía los patrones de los pueblos de indios por su vaguedad e indeterminación, el nombramiento y destitución de los gobernadorcillos debía amoldarse a esta realidad. En último término, Manila dejó en manos de los jefes de provincia la designación de las autoridades locales en función de "lo que exijan las circunstancias del momento". Un incierto criterio que la propia administración reconoció que podía dar lugar a todo tipo de abusos, como el cobro ilegal por expedición y multiplicación de títulos. Estas hipotéticas "extralimitaciones" responderían a las "condiciones de moralidad" de cada jefe de provincia. En último término, supuso un explícito reconocimiento de la corrupción como uno de los obstáculos a superar para alcanzar el objetivo de extender las estructuras del Estado colonial. Manila se defendió de la falta de reglamentación arguyendo que las autoridades provinciales podrían cometer estos abusos con decreto o sin decreto, "nunca faltan medios, cuando se quiere, de eludir la ley", y su papel estaría reservado a castigar estas posibles -y factibles- arbitrariedades. La Sección de Gobierno se decantó por no reglamentar

situación de los que abrazaban la Religión católica, con cargas y tributos que no ha tenido valor para imponer a los que permanecían infieles; y éste es el principal error...El que permanece infiel, no puede llegar a pagar más de cinco pesos en toda su vida; y el nuevo cristiano, aun dispensándole los diez años, puede llegar a pagar hasta noventa pesos. ¿En qué ley económica cabe llamar a esto gracia, y venderlo como favor?”; PÉREz, 1902, p. 42. Una medida similar propuso Fernando Primo de Rivera, militar que subrayó el grado de riqueza alcanzado por algunos "igorrotes", la exigua cantidad que pagaban por el vasallaje y la necesidad de contar con más fondos para financiar campañas militares; PrIMO DE RIVERA, 1881, pp. 14-15 y 18-19. El incremento de las imposiciones tributarias a finales de siglo provocó sublevaciones en estas demarcaciones, como la de Bontoc de 1894; Sсотт, 1975, pp. 173-175.

24 Expediente de nombramiento de gobernadorcillo de Bacong y Banguinay, 1888. PNA, SEG, provincia de Lepanto, legajo 116, rollo 6364.

25 El itinerario descrito y las reuniones que mantuvo con las autoridades coloniales y élites nativas de las provincias que atravesó fueron recogidos en PRIMO DE RIVERA, 1881. 
el nombramiento y destitución de gobernadorcillos y subalternos de las rancherías de "igorrotes", pero tampoco de los difusos deberes y obligaciones de estas poblaciones.

Esta indefinición legislativa motivó nuevas exposiciones de los jefes provinciales que mostraron a Manila los problemas existentes a la hora de organizar las rancherías. Dos años más tarde, el 9 de diciembre de 1890, el Gobernador Político-Militar de Amburayán solicitó autorización al Gobierno General de Filipinas para celebrar nuevas elecciones en las rancherías bajo su mando ${ }^{26}$. La autoridad político-militar reconoció la confusión existente tras comprobar que sus homólogos de las provincias de Ilocos Sur y La Unión no habían seguido un "criterio fijo" en el nombramiento de gobernadorcillos de "infieles" de sus respectivas demarcaciones. El Gobernador de Amburayán alertó de la necesidad de una reorganización debido a la inexistencia de jueces mayores y de cabezas de barangay en estas rancherías. El resultado de esta deficiente y exigua organización era el notable perjuicio que bajo su óptica suponía para "los intereses del Estado":

La falta de cabezas de barangay y de jueces de ganado motiva el que no haya verdaderos padrones y que se desconozca la riqueza pecuaria del distrito siendo por esta causa muy numerosas las ocultaciones de tributos y frecuentes robos de reses, este abandono es tanto más punible, cuanto que se trata de una raza que como los de Benguet, Tiagan y parte de Lepanto, se halla sometida al gobierno de la metrópoli desde hace más de cien años, sin embargo difiere mucho de aquellos distritos, cuyo régimen gubernativo revista ya todos los caracteres de asimilación para su progreso moral y material $^{27}$.

Un perjuicio eminentemente económico, según se reconoció abiertamente, con el agravante de que se trataban de unos grupos étnicos ya "asimilados" para alcanzar su progreso moral y material, la grandilocuente aspiración que soterró o engalanó el objetivo real de imponer nuevas exacciones. Para alcanzar este objetivo el Gobernador de Amburayán propuso la sustitución de los pedáneos. Bajo su punto de vista, la falta de reglamentación electoral y la libertad que se había otorgado a estos pedáneos había motivado que cada localidad continuase regentada por el Tribunal o consejo de los ancianos, una institución prehispánica. En este sentido propuso menoscabar su influencia o al menos preparar a los "infieles" para que este consejo desapareciese en un breve plazo, erosión para la que contaron con la entusiasta anuencia de los eclesiásticos ${ }^{28}$.

\footnotetext{
26 Expediente de nombramiento de gobernadorcillos en Amburayán, 1890. PNA, SEG, provincia de Mountain Province, legajo 168, rollo 6447.

27 Ibidem.

28 Recogida sin ambages en la obra de Ángel Pérez: "Su inteligencia es bastante despierta y susceptible de pronta civilización, si se adoptan con ellos medidas que les hagan olvidar sus costumbres actuales; pues aun cuando rige en todo el territorio el mismo sistema gubernativo que en el resto de las islas, fuera de las expediciones y privilegios que gozan estos habitantes, suele suceder con mucha frecuencia que la influencia y autoridad de sus ancianos se sobrepone a la autoridad del Gobernadorcillo, hasta el punto de que las órdenes del Jefe del Distrito pasan por el tamiz de la opinión de aquellos antes de ser cumplimentadas"; Pérez, 1902, pp. 235-236. No resulta casual que este misionero propusiera deportar a dos ancianos por ranchería, como principales responsables y/o instigadores, por cada muerte que se produjese en enfrentamientos entre rancherías en el caso de que no apareciesen los autores; PérEz, 1902, p. 83. A los ojos de los frailes, el Tribunal
} 
Frente a la decidida estrategia intervencionista propuesta por el Gobernador Político-Militar de Amburayán, el Negociado propuso continuar con una vía contemporizadora para evitar "quebrantar la forma de gobierno patriarcal a que estas gentes vienen acostumbrados" y recordó que las reformas que afectaban a la tradición de los pueblos eran siempre de "índole muy delicada". De forma indirecta, el Negociado alertó de la posibilidad de que estas medidas provocasen una de las frecuentes estampidas de estas comunidades. Por eso aconsejó adoptar este tipo de disposiciones únicamente en caso de "necesidad que lo justifique". Para reforzar sus argumentos el Negociado trajo a colación la legislación electoral, aplicable únicamente a los pueblos "ya constituidos civilmente". El Negociado autorizó la renovación de los cargos concejiles "en la forma en que se ha venido haciendo siempre" y preguntó a Manila y a los comandantes de las demarcaciones de Tiayan, Ipayaos y Quiangan si eran partidarios de aplicar las recetas de su homólogo de Amburayán.

Los gobernadores de estas demarcaciones secundaron la estrategia intervencionista propuesta por su homólogo de Amburayán. A la altura de febrero de 1892 el Gobernador de Itaves designó a los justicias -subalternos de la autoridad municipalpreviamente elegidos por los principales de su distrito y les entregó su título correspondiente con el objetivo de que "estos kalingas empiezan a disfrutar los gérmenes de su futura civilización, y por consiguiente respeten y acaten a la persona constituida en autoridad" ${ }^{29}$. Una deriva institucionalizadora que recibió el beneplácito del Gobierno General de Manila, reveladora de los esfuerzos finiseculares del Estado colonial por extender y reforzar los tentáculos de la administración.

No resulta casual que en el fragmento anterior se hiciese hincapié en la importancia del título -y no exclusivamente en su vertiente económica- y el respeto y acato de la autoridad. Los rituales de transferencia de poder, y los símbolos y lenguajes que representaron y marcaron este poder, desempeñaron un papel de primer orden en las representaciones colectivas forjadas en el mundo colonial. En este caso concreto, en la teatralización de la sumisión y la obediencia hacia las autoridades españolas y el modelo de organización socioeconómico, político y religioso que representaron. Paralelamente, este acto también supuso la adquisición de una nueva legitimidad y alianza por parte de los "principales igorrotes" dentro del nuevo entramado de poder colonial, aquella que reforzó su estatus elitista y dominante respecto a aquellos subalternos de su mismo grupo étnico o hacia otros enemigos de comunidades distintas. Desde Manila se impulsó esta legitimación honorífica y se expidieron títulos de gobernadorcillos para rancherías "igorrotes" con el fin de dotarlos de mayor solemnidad y prestigio que los anteriores emitidos por los gobernadores provinciales. Paralelamente, la nueva carga simbólica también sirvió para castigar a los cargos subalternos que fallaron en el desempeño de sus responsabilidades. Según reconoció

de ancianos chocó con su aspiración de controlar las principalías indígenas, de ahí las medidas coercitivas propuestas por los religiosos.

29 Los "kalingas" fueron una de las etnias de las montañas de Luzón a menudo englobada bajo el genérico término de "igorrote", SÁnchez Gómez, 2003, p. 20. 
el Gobernador Político-Militar de Lepanto, la retirada de un título era considerada por los "igorrotes" como "un severo castigo" 30 .

Los lenguajes simbólicos que teatralizaron el juego de poderes entre colonizadores e "igorrotes" estuvieron marcados por un profundo sincretismo. Los ejemplos son sugerentes. El 3 de febrero de 1880 el Gobernador Político-Militar de Abra informó del nombramiento de un gobernadorcillo de "igorrotes" a propuesta de un grupo de "igorrotes" alzados de las rancherías de Guinaanes situadas al este de la Gran Cordillera (concretamente las de Pudong, Galdan, Magtenga y Guinaang) ${ }^{31}$. Tras presentarse en la cabecera de la provincia, y en nombre de un "convecino", ofrecieron sumisión al rey Alfonso XII y pidieron que se nombrase gobernadorcillo a uno de ellos, llamado Saguinday. El Gobernador Político-Militar le dio posesión "según costumbre", es decir, según los cánones de un ritual de carácter medievalizante consistente en la entrega de un bastón y la expedición de un certificado una vez rendido vasallaje, reconocimiento que debían renovar anualmente ${ }^{32}$. El tributo, en este caso concreto en forma de tres fardillos de tabaco, supuso la subordinación de estos pueblos "salvajes" sin cristianizar a las autoridades coloniales. Un proceso que finalizó con el reconocimiento por parte de Manila del proceder del Jefe Político-Militar, "reconocida la conveniencia de que las relaciones con las razas alzadas se intimen a fin de reducirlas" ${ }^{33}$.

\section{LAS ELECCIONES DE GOBERNADORCILLOS EN LAS POBLACIONES "REDUCIDAS": EL CASO DE ROSARIO (LA UNIÓN)}

Una vez reducidas, las poblaciones celebraron procesos electorales marcados por las dinámicas comunes a otras provincias, pero también por una serie de rasgos distintivos y específicos de estas demarcaciones. Este comportamiento dual es fácilmente perceptible en las elecciones que tuvieron lugar el 2 de abril de 1893 en el pueblo de Rosario de la provincia de La Unión ${ }^{34}$. El proceso electivo actuó de catalizador social y a través de las anejas denuncias de irregularidades permite entrever la estructuración y funcionamiento del poder local de este "naciente pueblo", es decir, en una localidad de reciente creación. Bajo la óptica del Gobernador Civil que asistió a las votaciones, el nepotismo y el clientelismo era una verdadera "losa de plomo" que asolaba a esta población por la "influencia funesta" que ejercía la "rica familia Bernal”. Según el Jefe político, esta casta había conseguido imponer en el pueblo una temida e influyente "dinastía de gobernadorcillos hereditaria" cuyo poder era necesario corregir.

\footnotetext{
30 Expediente de nombramiento de gobernadorcillo de Bacong y Banguinay, 1888. PNA, SEG, provincia de Lepanto, legajo 116, rollo 6364.

31 Expediente de nombramiento de gobernadorcillo de las rancherías de Pudong, Galdan, Magtenga y Guinaang, 1880. PNA, SEG, provincia de Abra, legajo 2, rollo 6444.

32 Más detalles de este ritual, en Reconocimiento de vasallaje, 1892.

33 Expediente de nombramiento de gobernadorcillo de las rancherías de Pudong, Galdan, Magtenga y Guinaang, 1880. PNA, SEG, provincia de Abra, legajo 2, rollo 6444.

34 Expediente de nombramiento de gobernadorcillo del pueblo de Rosario, 1893. PNA, SEG, provincia de La Unión, legajo 112, rollo 6443.
} 
El fundador de la dinastía fue Jauro Bernal, antiguo gobernadorcillo y dueño de la mayoría de las tierras de los montes del pueblo por derecho de "primi ocupantis" o derecho de ocupación. Escudado en esta prerrogativa, similar a la esgrimida por conquistadores y órdenes regulares desde el siglo XVI para acaparar propiedades y tributos $^{35}$, utilizó estas tierras para decidir quién podía sembrar en ellas palay de monte -un tipo de arroz-. En contrapartida, estos cultivadores debían pagar a Bernal "su vasallaje". Favorecido por la indefinición propiciada por la normativa, Jauro Bernal también fue acusado de haber establecido una ranchería de "igorrotes" que no figuró en ningún repartimiento ni padrón. La ocultación de tributos por parte de las élites nativas fue uno de los delitos más perseguidos por la administración colonial, máxime si se compara con la laxitud que demostraron con otro tipo de ilegalidades ${ }^{36}$. Para la administración colonial, la implantación de los cargos subalternos en las rancherías de "igorrotes" también aspiró a incorporar una parte de la tributación subrepticia que las élites indígenas de estas demarcaciones dejaron descansar sobre los hombros del conjunto de la población. Un proceso de institucionalización tributaria que tampoco cortó de raíz los recargos que las élites nativas aplicaron a la tributación con el objetivo de ganarse el favor de los principales "igorrotes", colaboradores imprescindibles para llevar a buen puerto la recaudación ${ }^{37}$. En definitiva, estos beneficios constituyeron uno de los engranajes esenciales del pacto colonial trabado entre colonizadores y elites nativas ${ }^{38}$.

Tras haber ostentado el cargo de gobernadorcillo en sucesivas ocasiones, Jauro Bernal lo "transfirió" a su sobrino, Antero Estacio Bernal, también acusado de cometer irregularidades, concretamente en la redención ilegal de polistas ${ }^{39}$. En lugar de haber destinado los fondos procedentes de este concepto a la construcción de una escuela, Antero los había entregado al fundador de la dinastía, fraude que había sido neutralizado por el Gobernador Civil y la Administración de Hacienda. Los abusos continuaron con el siguiente gobernadorcillo, Eusebio Bernal, hijo de Jauro y primo de Antero, también acusado de haber redimido polistas ilegalmente con la excusa de adquirir instrumentos para la banda de música. Antes de abandonar el cargo, Eusebio fue acusado de amedrentar a los electores para que le sucediese al frente del pueblo su

35 Los perfiles económicos del derecho de conquista son desgranados en Fradera, 2005, pp. 450-451.

36 Corruptelas detalladas por HUETZ DE LeMPS, 2006.

37 Sobrecargos tributarios que también fueron recogidos por Ángel Pérez: "El tributo es un gran recurso para los principales....sin personal que los vigile, todo se hace según sus costumbres y de acuerdo con el consejo de ancianos, sin que signifique nada para ellos el Gobernadorcillo y demás justicias, que si bien recaudan y entregan el arbitrio de matanza y reconocimiento de vasallaje, consta al que suscribe que no reina la mayor moralidad en dicha recaudación, pues exigen mucho más de lo que corresponde, imponiéndose y castigando por sí mismos al que los denuncia”; PéREZ, 1902, p. 92.

38 Abusos a menudo silenciados por la dicotómica historiografía nacionalista, deriva que también ha minusvalorado la visión negativa sobre los "igorrotes" interiorizada por sectores de los ilustrados filipinos, olvidos rescatados por Sánchez Gómez a raíz de los debates generados por la Exposición de Filipinas en Madrid de 1887; 2003, pp. 224-264. El papel del consentimiento nativo dentro de la ingeniería colonial es escudriñado en BLANCO, 2009, p. 39.

39 Los polos fueron prestaciones obligatorias para los indígenas desde la conquista basadas en trabajos en obras públicas, infraestructuras, etc..., que pervivieron a lo largo del siglo XIX. Fueron progresivamente reducidos o redimidos en metálico, sistema que propició la comisión de numerosos abusos por las élites indígenas y peninsulares; SÁNCHEZ GómEZ, 2000, pp. 577-599. 
hermano, Pedro Bernal, aupado al primer lugar de la terna en las últimas elecciones. El Gobernador Civil desaconsejó a Manila la designación de éste último para dirigir el pueblo con el objetivo de atajar el "exclusivo dominio de esta afortunada familia que todo lo acapara y todo se lo apropia sin que nadie pueda quejarse por el terror que les inspira tan continuada sucesión" ${ }^{40}$. El poder atesorado por la familia Bernal en esta principalía le permitió coaccionar a los cultivadores de sus tierras, pero también le respaldó para presionar al propio Gobernador Civil, quién aseguró a Manila haberse visto "asediado" con "especiales recomendaciones de muy baja índole" para que Pedro Bernal fuese designado gobernadorcillo.

El Jefe político, en nombre de la "moralidad" y del "buen nombre de la administración", desechó al candidato de los Bernal, pero también al segundo de la terna, Basilio Nejal, "infeliz" de tal "estupidez" que fue buscado ad hoc por esta dinastía para allanar el camino a los Bernal ${ }^{41}$. Finalmente, "vistos los amaños y exacciones" el Gobernador Civil propuso anular la "preparada" elección o bien nombrar a Mariano Posadas, "persona de arraigo" que sin embargo no había sido elegido entre los tres miembros de la terna. Es decir, pese a la grandilocuencia y la presunta búsqueda de la legalidad, el Gobernador político propuso atajar una ilegalidad con otra, la recurrente doble moral de los funcionarios coloniales en Filipinas ${ }^{42}$.

Junto al dictamen del Gobernador Civil, las facciones en disputa por el poder elevaron sendas exposiciones que permiten profundizar en los perfiles que adoptó la pugna por el control de la principalía. La primera de ellas, firmada por Mariano Posadas y Cesáreo García, fue presentada por un grupo de cabezas de barangay que denunciaron la "monopolización" del cargo de gobernadorcillo por los Bernal durante los últimos cinco bienios. Incluso fueron más allá y utilizando un lenguaje formal y sumiso sugirieron, por acción u omisión, la complicidad de las autoridades coloniales a la hora de permitir que los miembros de esta familia se votasen ellos mismos y sobornasen a los electores en sucesivas votaciones, prácticas prohibidas por la ley electoral. Bajo la óptica de los denunciantes, el decidido interés por ostentar este cargo se explica por la necesidad de encubrir los sucesivos abusos de los miembros de la familia y para ocultar sus negocios especulativos con el Real Haber ${ }^{43}$.

Por su parte, Eusebio Bernal, gobernadorcillo saliente, presentó ante el Gobernador Civil una exposición atacando a los líderes de la facción rival, Mariano Posadas -candidato propuesto por el Jefe político- y Cesáreo García, su "hijo político". En primer lugar lanzó la hipótesis de los presuntos intereses personales que albergaron al postularse al cargo. En segundo lugar, aportó detalles en torno a la supuesta incapacidad de ambos para ser electores o elegibles. A Mariano Posada lo acusó -respaldado en sentencias- de ser un "jugador consumado", tanto de naipes como de gallos, y de

40 Expediente de nombramiento de gobernadorcillo del pueblo de Rosario, 1893. PNA, SEG, provincia de La Unión, legajo 112, rollo 6443.

41 El recurso a este lenguaje denigratorio se erigió en una herramienta más de los colonizadores para marcar distancias con los colonizados en términos de prestigio y dignidad. Una estrategia retórica y discursiva similar adoptaron los franceses en Indochina; SAADA, 2007, pp. 55-56.

42 Prácticas analizadas en Huetz De LemPs, 2009, pp. 143-156.

43 En el escrito de denuncia no se aportan más detalles de esta acusación sobre la utilización personalista del Real Haber. 
estar "amancebado". Por su parte, los ataques dirigidos al "discípulo" de éste estuvieron centrados en cuestiones materiales, en su presunta incapacidad por no tener oficio ni bienes de consideración, cualidades fijadas en la legislación y apreciadas por las autoridades coloniales como avales por las funciones recaudatorias delegadas, reveladoras a su vez de las fuentes del poder social:

A D. Cesáreo no se le conoce poseer algún pedazo de sementera, no se le conoce dedicar en la profesión pecuaria, ni horticultor. En este pueblo, señor Gobernador, el que no se dedica a uno de los arriba expresados debía mantenerse con alguna profesión reprobada por la ley. Solo tiene una casita, cuyo aspecto, no responde de su elevado cargo de teniente primero actual, pues al menor soplo de un vendaval se arrollaría, como se puede ver hoy mismo. El que carece de alguna renta y no trabaja, ¿no es el que trata el dicho art. $4^{\circ}$ que no tiene oficio o modo de vivir conocido? ${ }^{44}$.

Manila finalmente anuló las elecciones por el incumplimiento de los requisitos legales por parte de los elegidos, incapacidad detallada en los informes y exposiciones presentadas por las facciones. La convocatoria de nuevas elecciones también echó por tierra el amaño propuesto por el Gobernador Civil de nombrar directamente a Mariano Posadas sin pasar por las urnas. No obstante, la nueva votación arrojó un resultado que satisfizo los intereses del Jefe político. Los Bernal quedaron fuera de la terna mientras que un miembro de los Posadas, Juan, resultó el candidato más votado. Juan Posadas compartía con los dos restantes de la terna todos los requisitos morales y materiales, incluida la apreciada afección por los "españoles" y a las "instituciones vigentes". De nuevo la "suficiente posición social" del primero de la terna resultó decisiva en la designación de Juan Posadas como gobernadorcillo, frente a la "regular posición" del maestro de escuela elegido en segundo lugar y la "endeble" del tercer propuesto. La preferencia de las autoridades coloniales por las élites "igorrotes" que tuviesen capacidad de respaldar con su patrimonio, bien adelantándolos o haciendo frente a los impagos, los tributos asignados por la administración.

En suma, el desvelamiento de las corruptelas desplegadas en las dos elecciones celebradas en la principalía de Rosario permiten discernir una serie problemas comunes al resto de principalías filipinas, pero también una serie de rasgos particulares derivados de la organización de las zonas habitadas por "igorrotes". Entre las pautas genéricas habría que subrayar el papel central de la familia en las luchas electorales filipinas, a partir de un concepto extenso de familia que incorporó prácticas de compadrazgo y padrinazgo asociadas a los nuevos baptismos que tuvieron lugar en estas demarcaciones ${ }^{45}$. Esto derivó en prácticas clientelares entre parientes y un creciente nepotismo. Los Bernal fueron un ejemplo acabado. Estos lazos familiares constituyeron una verdadera plataforma de poder que permitió a los caciques nativos hacer frente o modular el poder de las autoridades coloniales, a las cuales llegó a presionar, capacidad que despertó la preocupación del Gobernador Civil de La Unión. Una fortaleza también forjada en los usos políticos de sus recursos productivos y

44 Expediente de nombramiento de gobernadorcillo del pueblo de Rosario, 1893. PNA, SEG, provincia de La Unión, legajo 112, rollo 6443.

45 Escrutadas por Dizon, 2011, pp. 367-398. 
en la utilización privativa y fraudulenta de los resortes de poder municipal, como la apropiación de polos o las coacciones a los electores. El extendido recurso a testaferros y lugartenientes ${ }^{46}$, denominados "hijos políticos" o "discípulos", también estuvo presente en estas demarcaciones, donde tampoco fue ajena la extendida corrupción de las autoridades coloniales. El interés por ostentar el cargo de gobernadorcillo en esta principalía aporta nuevos mimbres para profundizar en el debate del apetito que despertó este puesto en las zonas alejadas de los principales centros de poder ${ }^{47}$. Las denuncias generadas por los Bernal y los Posadas constituyen una buena muestra de esta pugna, contienda que forzó unas segundas elecciones, reveladoras de la fragilidad de considerar a las sociedades nativas como dóciles, aletargadas y desmovilizadas ${ }^{48}$.

Por el contrario, las elecciones de Rosario también arrojan unos sellos distintivos que las diferencian del resto de provincias filipinas. Enclavada en una zona de frontera interior, la creación de la principalía permitió a las élites nativas el acaparamiento de importantes propiedades por derecho de ocupación y su consiguiente uso político, apropiaciones menos usuales a finales del siglo XIX en las primeras zonas colonizadas. Este carácter fronterizo también determinó la formación de rancherías no declaradas, amparadas por el carácter seminómada de estas poblaciones y por la vaguedad de la legislación. El cobro de nuevos impuestos era uno de los motores de la política de reducciones, razón que explica la menor transigencia de las autoridades coloniales con los delitos de carácter económico. Las actas electorales corroboran que las prácticas clientelares de los Bernal habían sido consentidas durante años, pero el descubrimiento de una ranchería de "igorrotes" no declarada, cuyos tributos eran percibidos subrepticiamente por los Bernal, influyó poderosamente en el giro experimentado por el Gobernador Civil. Y, por extensión, permite subrayar el peso que desempañaron los condicionantes económicos en la expansión interna proyectada en estas demarcaciones.

\section{LAS INQUISICIONES SOBRE GOBERNADORCILLOS "IGORROTES": RECAUDADORES, PARAMILITARES E INFIELES A EXAMEN}

La diligencia recaudatoria aparece mencionada abiertamente como un mérito en los informes confeccionados sobre los "igorrotes" postulados a gobernadorcillo, inquisiciones que aportaron sugerentes detalles para profundizar en las disimilitudes que entrañaron los procesos electorales en las zonas "salvajes". Los informes de conducta elaborados sobre los candidatos a dirigir los pueblos y rancherías mostraron sin ambages las preferencias de las autoridades coloniales a la hora de seleccionar a los aspirantes "igorrotes":

habría de influir poderosamente para la reducción de los demás infieles de aquel pueblo con razón a sus condiciones sociales superiores a los demás, en su cargo de

\footnotetext{
46 Señalado en Inarejos Muñoz, 2011, p. 757.

47 Debate desgranado en Huetz de Lemps, 1997, 436-437; Inarejos Muñoz, 2012a, pp. 208-209.

48 Lugares comunes que ya puso en entredicho Alatas, 1977.
} 
cabeza de barangay ha demostrado bastante actividad y celo en la recaudación de los impuestos, su conducta moral y política es intachable ${ }^{49}$.

El fragmento anterior pertenece al contundente dictamen que emitió el Gobernador Político-Militar de Abra sobre uno de los candidatos a dirigir la principalía de San Quintín durante el bienio de 1895-1897, el "igorrote" Pagavan. Este retrato resultó decisivo para que Manila ratificase el apoyo brindado por el Jefe provincial a este "infiel", eficiente recaudador de impuestos, en perjuicio de su opositor Mariano Crespo, cabeza de barangay que había demostrado "poca aptitud por su falta de actividad y celo en el cumplimiento de sus deberes" 50 . A falta de otras tachas legales que lo inhabilitasen para el cargo, la eficacia recaudatoria fue incluso capaz de eclipsar la poderosa influencia de los frailes. En el informe elaborado por el párroco misionero de la localidad se subrayó que Pagavan fue bautizado después de haber sido elegido en las elecciones ${ }^{51}$, una sensible diferencia respecto a Mariano Crespo, cristiano. No obstante, para el Gobernador Político-Militar, partidario de la estrategia conciliatoria a la hora de reducir a estas poblaciones, la pertenencia de Pagavan a la élite nativa y su reciente conversión al cristianismo ${ }^{52}$, lejos de constituir un obstáculo, sería vista como un ejemplo a imitar por el resto de "infieles" del pueblo dentro del interés último de incorporarlos a la grandilocuente senda del progreso y la civilización. Y, en último término, a tributar.

Al igual que ocurrió en otras zonas del archipiélago, el escrutinio de las cualidades de los distintos candidatos dejó al descubierto la competencia entablada entre las distintas ramas de la administración colonial por colocar a los aspirantes que comulgasen con sus intereses. Este soterrado pulso salió a la luz durante las elecciones celebradas en Benguet en 1895 a raíz del conflicto entablado entre el párroco de la localidad, partidario del elegido en el primer lugar de la terna, y el Gobernador Político-Militar de Benguet, firme defensor del aspirante elegido en segundo lugar. La confrontación entre autoridad religiosa y autoridad cívico-militar trascendió más allá del debate concreto de las aptitudes de los candidatos a gobernadorcillo:

dando la vara de gobernadorcillo a Fernando Caoile, ha de reinar en Benguet el partido y la influencia frailuna; porque Caoile se echará en brazos de los frailes para con ellos defender a sus parientes y a cuantos hacen causa común con éstos...los frailes están divorciados del principio de autoridad, no más que por defender a quienes solo ellos consideran dignos de defensa... a su sombra y sin duda con su aquiescencia se establecerá en la cabecera del distrito de Benguet el imperio del fraile sobre el de la autoridad gubernativa ${ }^{53}$.

49 Expediente de nombramiento de gobernadorcillo de San Quintín, 1895. PNA, SEG, provincia de Abra, legajo 4 , rollo 6368 .

50 Ibidem.

51 Las medidas de racionalización hacendística implantadas durante el siglo XIX motivaron que en 1849 fuese decretada la obligación de adoptar apellidos a los habitantes del archipiélago; FrADERA, 1999, pp. 133190; Blanco, 2009, p. 3.

52 Estrategia analizada en Dizon, 2011, p. 387; RAFAEL, 1993.

53 Expediente de nombramiento de gobernadorcillo de Benguet, 1895. PNA, SEG, provincia de Mountain Province, legajo 168, rollo 6447. 
Del testimonio anterior se desprende que las provincias del norte de Luzón tampoco fueron ajenas a un conflicto presente desde el inicio de la colonización ${ }^{54}$. La desazón del Gobernador Político-Militar con el párroco se vio acrecentada por el método empleado por el cura para dar a conocer sus informes sobre los candidatos: el envío directo a Manila sin pasar por manos del jefe provincial. Unos informes que contienen jugosos detalles para indagar en los perfiles sociológicos de la élite "igorrote". El perfil que dibujó el Gobernador Político-Militar sobre el candidato apadrinado por el cura resultó demoledor ${ }^{55}$. Presentó a Fernando Caoile como un hombre activo y trabajador que hablaba algo el castellano, pero de condición "hipócrita...nada seria ni formal" por haber interpuesto una denuncia supuestamente falsa contra el anterior jefe del distrito. Según la autoridad provincial, Caoile estaba emparentado con varios vecinos procesados y encarcelados "apadrinados" por el párroco ${ }^{56}$. Además era "aficionado" a los "feos vicios" de la bebida y el juego, "vicios" que relacionó con las deudas que había contraído con Hacienda en calidad de cabeza de barangay, un demérito a la sazón decisivo para las autoridades de Manila a la hora de discriminar a los candidatos.

El juicio que emitió sobre el segundo aspirante, Toribio Valdés, resultó categórico. A los ojos del Gobernador Político-Militar era la única persona apta para el cargo. Hablaba castellano, era inteligente, honrado, trabajador y había desempeñado con solvencia varios cargos subalternos (directorcillo de la ranchería de Baguio, cabeza de barangay, escribiente de la Junta de Composición de terrenos e intérprete oficial de la comandancia). Durante el disfrute de estos puestos no había contraído ninguna deuda con Hacienda, "lo cual indica su interés por los del Estado y por los individuos de su cabecería". En palabras del Jefe provincial, no era "fácil encontrar otro indio que le iguale". Catalogado como "enemigo de adulaciones y compadrazgos", se había mantenido al margen de las luchas faccionales, a diferencia del alienado candidato del párroco. A estas "sobresalientes condiciones" sumó su afecto por el "principio de autoridad" y a "todo lo que sea españolísimo". Obediencia y sumisión, dos cualidades marciales de las que se empapó bien durante los ocho años de servicio que prestó como cabo de la Guardia Civil con una "limpísima" hoja de servicios. Su

54 Pulso que también fue recogido por Ángel Pérez desde la defensa de los privilegios de las órdenes religiosas en las provincias norteñas: "No es posible escribir la historia política de las Islas Filipinas, durante la dominación española, separada de la historia de las Órdenes Religiosas; tal ha sido la unión y enlace que ha existido en todas las épocas entre ambas. Generales y religiosos, auxiliándose mutuamente, realizaban una de las epopeyas más heroicas y gloriosas que registra la historia de la Patria española. Cuantas veces se ha roto esa unión y concordia, queriendo sobreponerse el elemento político al religioso, otras veces se ha marchitado la corona de verde laurel..."; PÉREZ, 1902, p. 5. Para profundizar en esta pugna véase la monografía de BLANCO ANDRÉs, 2012.

55 Para reforzar su juicio ante Manila el Gobernador Político-Militar aseguró haber tenido en cuenta la circular reservada emitida por el Gobierno General de Manila de 27 de febrero de 1893 relativa al prestigio de la autoridad: “...no puedo menos de dejar empeñada mi palabra de honor, para que ella sirva a V. E. de garantía de que mis informes son exactos"; Expediente de nombramiento de gobernadorcillo de Benguet, 1895. PNA, SEG, provincia de Mountain Province, legajo 168, rollo 6447.

56 La alineación de los religiosos en las luchas de poder por el control de las principalías filipinas es abordada en InAREJos MuÑoz, 2012b, pp. 1-16. 
dictamen fue concluyente: "no encuentro una sola tacha que ponerle y sí en cambio es acreedor a aplauso bajo cualquier aspecto que se le considere" ${ }^{57}$.

Estas virtudes marciales también figuraron en el bagaje del tercer aspirante. El gobernadorcillo saliente también había servido en el Ejército y a pesar de que había desempeñado varios cargos municipales con anterioridad, el Gobernador Político-Militar desaconsejó su nombramiento por tratarse de un anciano que debía permanecer recluido en su hogar. Un hombre "honrado y de bien" pero sin dotes de mando para hacerse respetar que había alcanzado el cargo en el bienio precedente por descarte:

si en el bienio anterior se le propuso para el cargo de gobernadorcillo que hoy desempeña fue por medio o modo parecido a lo que se hizo con el Rey Wamba; no había en el pueblo de La Trinidad una sola persona honrada a quien confiarle el bastón, y tan fue así, que se prefirió elegir en segundo lugar un igorrote, antes de nombrar un cristiano $^{58}$.

En el fragmento anterior el jefe provincial aludió de nuevo a la "corrupta" clientela del párroco ${ }^{59}$, pero también dejó patente la preferencia existente por los cristianos sobre los "igorrotes" a la hora de seleccionar a las élites nativas para dirigir la administración local. Unos criterios religiosos o morales que, no obstante, permanecieron subordinados a la "honradez". Honradez traducida o entendida como presteza en la recaudación de impuestos. Unos criterios selectivos que decantaron la elección de Benguet. En sus informes de conducta el misionero defendió a Fernando Caoile, omitió sus deudas con Hacienda y restó importancia al hecho de ser "un apasionado a las bebidas alcohólicas". Bajo la óptica del fraile, cuando no se encontraba en estado de embriaguez desempeñaba sus funciones de cabeza de barangay con normalidad. Por el contrario, al segundo de la terna, Toribio Valdés, le acusó de no tener bienes raíces, de haber interceptado su correspondencia epistolar y de conducta nada ejemplar por "concubinato, con escándalo de todo el público" ${ }^{60}$. Entre el candidato apadrinado por el párroco, deudor a Hacienda, y el aspirante respaldado por el gobernador, eficiente recaudador pero "amancebado", los intereses económicos pesaron como una losa. Finalmente Manila nombró gobernadorcillo al candidato venerado por el Jefe provincial, convencido por el sinfín de aptitudes sobredimensionadas, como su pasado como agente coercitivo, pero sobre todo por no tener descubiertos con Hacienda ${ }^{61}$.

Junto a los móviles económicos y la conversión al cristianismo, las cualidades marciales se erigieron en un activo de primer orden a la hora de ganarse el favor de

57 Expediente de nombramiento de gobernadorcillo de Benguet, 1895. PNA, SEG, provincia de Mountain Province, legajo 168, rollo 6447.

58 Ibidem.

59 Por su parte, el párroco se defendió en su informe argumentando que la población de Benguet se componía de personas procedentes de varias provincias de Luzón que habían llegado a este pueblo para evitar la vigilancia de las autoridades de sus anteriores lugares de residencia y admitió que no destacaron precisamente por su honradez; Expediente de nombramiento de gobernadorcillo de Benguet, 1895. PNA, SEG, provincia de Abra, legajo 2, rollo 6444.

60 En las aptitudes del tercero de la terna el párroco coincidió con el dictamen del gobernador; Expediente de nombramiento de gobernadorcillo de Benguet, 1895. PNA, SEG, provincia de Abra, legajo 2, rollo 6444.

61 El dictamen fue concluyente: "toda vez que el elegido en primer lugar se halla incapacitado legalmente para ejercer dicho cargo por ser deudor a la Hacienda". 
las autoridades coloniales para alcanzar la vara de gobernadorcillo. Baste recordar que estas principalías fronterizas fueron punto de partida de expediciones militares destinadas a la reducción de poblaciones no sometidas ${ }^{62}$. Los informes de conducta de los aspirantes a dirigir principalías del norte de Luzón levantaron acta de las preferencias de la administración colonial a la hora de seleccionar al personal nativo para los puestos subalternos. Ismael Alzate y Astudillo, gobernadorcillo del pueblo de Bucay (provincia de Abra), fue condecorado por el Gobierno con el nombramiento de Caballero de la Orden del Mérito Militar blanca por los "servicios extraordinarios" que prestó al Gobernador Político-Militar en la expedición militar contra las comunidades fronterizas alzadas durante el bienio de $1877-1879^{63}$. También había destacado por la detención de varios ladrones de ganado durante el desempeño del cargo de Teniente de cuadrilleros, su "energía poco común para el mando" y "tan afecto a los españoles que cuantos llegan a su pueblo conciben de este indio un grato recuerdo". En suma, un conjunto de cualidades castrenses que determinaron su reelección para el bienio de 1879-1881 para un pueblo que reunía unas "especiales condiciones". Bucay fue el punto de partida de las expediciones militares que intentaron abrir el camino entre las provincias de Abra a Cagayán por "pasos no habitados u hostiles" ${ }^{64}$. Pero que también determinaron, a la sazón, su selección para viajar a la metrópoli y formar parte de la Exposición de Filipinas como intérprete y encargado del contingente de nativos enviado a la Península en 1887, cuando recibió la Cruz de Isabel la Católica ${ }^{65}$. Según retrató la prensa madrileña, para las autoridades coloniales españolas Ismael Alzate era el prototipo de igorrote soñado.

\section{CONCLUSIONES}

Marcadas por una legislación difusa, las circunscripciones habitadas por igorrotes experimentaron un comportamiento electoral definido por las particularidades del método electivo y las funciones de sus gobernadorcillos. La tradicional votación pseudocensitaria convivió o fue sustituida por designaciones directas de las autorida-

62 La paralización de la política de reducciones en los inicios de la colonización fue censurada y explicada por el agustino Ángel Pérez en virtud de estos móviles: "Pero lo que atrasó más esta reducción tan importante, fue el haberse frustrado las esperanzas de las opulentas minas de oro, que tanto movieron la codicia, pues todos los que fueron a este descubrimiento se soñaban ya Cresos y Midas"; Pérez, 1902, p. 11. De este condescendiente razonamiento, el fraile excluyó los intereses materiales de las órdenes religiosas que entraron en colusión con los indígenas, como la imposición de impuestos y el acaparamiento de propiedades, una de las razones de las reticencias de los "igorrotes" a someterse al yugo colonial. Para profundizar en el poderío económico de las órdenes religiosas en Filipinas y los derroteros que describió este patrimonio tras la independencia de España, véanse los trabajos de Delgado, 2009, pp. 233-254; 2011, pp. 145-166.

63 Expediente de nombramiento de gobernadorcillo de Bucay, 1879. PNA, SEG, provincia de Abra, legajo 2 , rollo 6444 .

64 Sobre estos trabajos, véase Primo de Rivera, 1881.

65 El resto de cualidades que reunió Alzate (propietario, maestro, su manejo del castellano, y sus buenas relaciones con los eclesiásticos y la principalía), y los detalles y repercusiones de su participación en la exposición, en SÁnchez Gómez, 2003, pp. 183-188 y 314-315; autor que lo definió como el personaje más destacado de la muestra y fiel colaborador del colonialismo español en Filipinas. Véase también ScotT, 1975, pp. 12-13. 
des coloniales, nombramientos que fueron justificados en función de las especiales características de estos grupos y núcleos de población. Estas peculiaridades determinaron las disímiles estrategias planteadas para ampliar el dominio colonial a estas demarcaciones. Las maniobras oscilaron entre las políticas contemporizadoras encaminadas a lograr una progresiva asimilación, con la imposición paulatina de tributos y la delegación progresiva de funciones y honores, o las intervenciones militares que intentaron subyugar a estas poblaciones por canales coercitivos. La indeterminación de la reglamentación y los problemas derivados de su aplicación práctica motivaron que el despliegue de estas políticas no fuese ajeno a prácticas corruptas por parte de las autoridades coloniales y de las élites nativas. Estas dinámicas son perceptibles en las poblaciones reducidas que celebraron procesos electivos, votaciones que estuvieron marcadas por parámetros comunes a otras provincias, pero también por una serie de rasgos distintivos y específicos. El papel central de la familia en las disputas electorales, los manejos clientelares, la capacidad de presión de las élites nativas, el interés por ostentar el cargo de gobernadorcillo o las arbitrariedades de los funcionarios coloniales fueron algunas de las pautas genéricas compartidas con el resto de provincias. El carácter fronterizo de las estas poblaciones determinó el sello distintivo que adquirieron las elecciones en estas poblaciones, marcadas por la nebulosa frontera establecida entre derechos y obligaciones y el incremento de la recaudación tributaria. Precisamente el peso de los condicionantes económicos en la expansión colonial proyectada en estas zonas marcaron los criterios selectivos que utilizaron las autoridades coloniales a la hora de reclutar a los caciques nativos. En esta criba ocuparon un lugar axial la eficacia y diligencia recaudatoria de los aspirantes a ocupar el poder municipal. Un requisito que no excluyó otras cualidades estereotipadas, como fueron las aptitudes castrenses y la preferencia por los candidatos evangelizados, en estrecha relación con la expansión militar y religiosa proyectada en estas fronteras interiores.

\section{REFERENCIAS BIBLIOGRÁFICAS}

Alatas, Syed H.

1977 The Myth of the Lazy Native. A study of the image of the Malays, Filipinos and Javanese from the $16^{\text {th }}$ to the $20^{\text {th }}$ century and its function in the ideology of colonial capitalism. London. Frank Cass.

Alonso Álvarez, Luis

2009 "La Administración española en las islas Filipinas, 1565-1816. Algunas notas explicativas acerca de su prolongada duración”. En Elizalde Pérez-Grueso (ed.), pp. 79-117.

ANÓNIMO

1892 Reconocimiento de vasallaje de remontados e infieles. Manila. Establecimiento tipolitográfico de Ramírez y Comp., Colección de "El Faro Administrativo".

AzCÁrRaga, Manuel de

1871 La reforma del municipio indígena en Filipinas. Madrid. J. Noguera. 
BANKOFF, Greg

1992 "Big Fish in Small Ponds: The Exercise of Power in a Nineteenth-century Philippine Municipality”. Modern Asian Studies. Cambridge, n² 26/4, pp. 679-700.

BLANCO, John David

2009 Frontier Constitutions. Christianity and Colonial Empire in the Nineteenth- Century Philippines. Berkeley. University of California Press.

BLANCO ANDRÉs, Roberto

2012 Entre frailes y clérigos. Las claves de la cuestión clerical en Filipinas (1776-1872). Madrid. CSIC.

Blumentritt, Ferdinand

1881 Organisation communale des indigènes des Philippines placées sous la domination espagnole. Paris. Bulletin de la Société Académique Indo-chinoise.

CAmacho, Marya Svetlana

2002 "Race and Culture in Spanish and American Colonial Policies". En McFerson (ed.), Mixed Blessing: The Impact of the American Colonial Experience on Politics and Society in the Philippines. Westport. Greenwood Press, pp. 43-74.

Celdrán Ruano, Julia

1994 Instituciones Hispanofilipinas del siglo XIX. Madrid. Mapfre.

Delgado Ribas, Josep María

2009 "Entre el rumor y el hecho: el poder económico del clero regular en Filipinas (16001898)". En Elizalde Pérez-Grueso (ed.), pp. 233-254.

2011 "In God we Trust. La administración colonial americana y el conflicto religioso en Filipinas”. En Delgado Ribas - Elizalde Pérez-Grueso (eds.), pp. 145-166.

Delgado Ribas, Josep María - Elizalde Pérez-Grueso, María Dolores (eds.)

2011 Filipinas, un país entre dos imperios. Barcelona. Bellaterra.

Dizon, Mark

2011 "Social and Spiritual Kinship in Early-Eighteenth-Century Missions on the Caraballo Mountains". Philippine Studies. Manila, nº 59, 3, pp. 367-398.

Elizalde Pérez-Grueso, María Dolores

2002 "La Administración colonial de Filipinas en el último tercio del XIX. Dos procesos contrapuestos: la reactivación del interés español frente a la consolidación de una identidad nacional filipina”. En Elizalde Pérez-Grueso (ed.), pp. 123-142.

2009 “Sentido y rentabilidad. Filipinas en el marco del Imperio Español”. En Elizalde PÉrez-Grueso (ed.), pp. 45-78.

ElizAlde PÉrez-Grueso, María Dolores (ed.)

2002 Las relaciones entre España y Filipinas, siglos XVI-XX. Madrid. CSIC - Casa Asia.

2009 Repensar Filipinas. Política, Identidad y Religión en la construcción de la nación filipina. Barcelona. Bellaterra.

Feced y Temprado, José

1867 Manual del gobernadorcillo en el ejercicio de sus atribuciones judiciales y escriturarias. Manila. Imp. Ramírez.

Fradera, Josep María

1999 Filipinas, la colonia más peculiar. La hacienda pública en la definición de la política colonial, 1762-1868. Madrid. CSIC, pp. 133-190.

2005 Colonias para después de un imperio. Barcelona. Bellaterra. 
2008 "La nación desde los márgenes (Ciudadanía y formas de exclusión en los imperios)". Illes i Imperis, Barcelona, $\mathrm{n}^{\mathrm{o}}$ 10/11, pp. 9-30.

Hidalgo Nuchera, Patricio

1995 Encomienda, tributo y trabajo en Filipinas (1570-1608). Madrid. Polifemo.

Huetz DE Lemps, Xavier

1990 "Les Philippines face au Fantôme du Gange: le cholera dans la seconde moitié du XIXe siècle". Annales de Démographie Historique. Paris, pp. 309-335.

1997 "La crise de la commune indigène a Manille au XIXe siècle". En El Lejano Oriente español. Sevilla. Cátedra General Castaños, pp. 419-442.

1998 "Nommer la ville: les usages et les enjeux du toponyme 'Manila' au XIXe. Siècle". Genèses. Paris, no 33, pp. 28-48.

2006 L'Archipel des épices La corruption de l'Administration espagnole aux Philippines (fin XVIIIe-fin XIXe Siècle). Madrid. Casa de Velázquez.

2009 "Una escuela colonial de disimulación”. En Elizalde Pérez-Grueso (ed.), pp. 143156.

INAREJOS MuÑoz, Juan Antonio

2011 "Reclutar caciques. La selección de las élites coloniales filipinas a finales del siglo XIX”. Hispania. Madrid, no 71/239, pp. 741-762.

2012a "La influencia moral en Asia. Práctica política y corrupción electoral en Filipinas durante la dominación colonial española". Anuario de Estudios Americanos. Sevilla, $n^{\circ} 69 / 1$, pp. 199-224.

2012b "La religión como arma de control colonial”. En XI Congreso de la Asociación de Historia Contemporánea, http://www.contemporaneaugr.es/files/.

Jesús, Edilberto C. de

1978 “Gobernadorcillo Elections in Cagayan". Philippine Studies. Manila, n 26, 1, pp. 142-156.

KRAMER, Paul

2006 The Blood of Government. Race, Empire the United States and the Philippines. Chapel Hill. The University of North Carolina Press.

2011 "Historias transimperiales. Raíces españolas del estado colonial estadounidense en Filipinas”. En Delgado Ribas - Elizalde Pérez-Grueso (eds.), pp. 125-144.

MAY, Glenn Anthony

1987 "Civic Ritual and Political Reality: Municipal Elections in the Late-19th Century Philippines". En MaY, A past recovered. Quezon City, New Day, pp. 30-52.

PÉrez, Fr. Ángel, O.S.A.

1902 Igorrotes: estudio geográfico y etnográfico sobre algunos distritos del norte de Luzón. Manila. Imprenta de "El Mercantil".

Phelan, John

2011 The Hispanization of the Philippines. Spanish Aims and Filipino Responses, 15651700. [1959]. Madison. The University of Wisconsin Press.

Primo DE RIVERA, Fernando

1881 Documentos referentes a la reducción de infieles e inmigración en las provincias de Cagayán y La Isabela dictados como primeras disposiciones adoptadas por el Excmo. Sr. Gobernador General D. Fernando Primo de Rivera, Marqués de Estella, con motivo de su visita a las del norte de Luzón. Manila. Establecimiento tipográfico del Colegio de Santo Tomás. 
RAFAEL, Vicente L.

1993 Contracting Colonialism: Translation and Christian Conversion in Tagalog Society Under Early Spanish Rule. Durham. Duke University Press.

SAADA, Emmanuelle

2007 Les enfants de la colonie. Les métis de l'Empire français entre sujétion et citoyenneté. Paris. Éditions La Découverte.

SÁnChEz GómEZ, Luis Ángel

1989 "Elecciones locales indígenas en Filipinas durante la etapa hispánica". En RoDAO (ed.): Estudios sobre Filipinas y las Islas del Pacífico. Madrid. AEEP, pp. 53-61.

1990 "Estructura de los pueblos de Indios en Filipinas durante la época española". En RoDAO (ed.), España y el Pacifico. Madrid. AECI, pp. 81-116.

1991 Las principalías indígenas y la administración española en Filipinas. Madrid. Universidad Complutense.

2000 "Los debates sobre la regulación de la prestación personal en Filipinas durante el siglo XIX". Anuario de Estudios Americanos. Sevilla, n 57, pp. 577-599.

2003 Un imperio en la vitrina. El colonialismo español en el Pacifico y la Exposición de Filipinas de 1887. Madrid. CSIC.

ScotT, William Henry

1974 The discovery of the Igorots: Spanish contacts with the pagans of Northern-Luzon. Quezon City. New Day Publishers.

1975 History on the Cordillera: collected writings on Mountain Province History. Baguio City. Baguio Printing and Pub. Co.

1988 "Introduction". En Fr. Antolín, O. P., Notices of the pagan igorots in the interior of the Island of Manila. Manila. UST Press, pp. XII-XVI.

1997 Barangay: Sixteenth-century Philippine culture and society. Quezon City. Ateneo de Manila University Press.

ZAMORA, Mario D.

1992 Los indígenas de las Islas Filipinas. Madrid. Mapfre. 